Case Report

\title{
Hyperparathyroidism Two Years after Radioactive Iodine Therapy in an Adolescent Male
}

\author{
Danielle L. Gomez and Dorothy I. Shulman \\ University of South Florida Diabetes Center, Department of Pediatrics, University of South Florida Morsani College of Medicine, \\ 12901 Bruce B. Downs Boulevard, MDC 62, Tampa, FL 33612, USA \\ Correspondence should be addressed to Dorothy I. Shulman; dshulman@health.usf.edu
}

Received 22 November 2013; Accepted 23 December 2013; Published 30 January 2014

Academic Editors: E. De Vries, M. Moschovi, and A. E. Scaramuzza

Copyright (C) 2014 D. L. Gomez and D. I. Shulman. This is an open access article distributed under the Creative Commons Attribution License, which permits unrestricted use, distribution, and reproduction in any medium, provided the original work is properly cited.

\begin{abstract}
Primary hyperparathyroidism is a very rare complication following radioactive iodine therapy. There is typically a latency period of more than a decade following radiation exposure and, therefore, it is observed almost exclusively in adults. Consequently, pediatricians are not aware of the association. We present a case of primary hyperparathyroidism due to a solitary parathyroid adenoma occurring in an adolescent male two years following radioactive iodine treatment for papillary thyroid carcinoma. Periodic screening of serum calcium following ablative doses of radioactive iodine for thyroid cancer may be justified even in adolescents.
\end{abstract}

\section{Introduction}

Primary hyperparathyroidism (P-HPT) is uncommon in children and adolescents with an incidence of $2-5$ in 100,000 [1]. Excess parathyroid hormone (PTH) secretion leads to hypercalcemia, hypophosphatemia, nephrocalcinosis, nephrolithiasis, and decreased bone density. Parathyroid adenoma is the most common cause of P-HPT in young patients, representing $65-90 \%$ of pediatric cases [1-4]. Multiglandular hyperplasia occurs in $16-27 \%$ of pediatric $\mathrm{P}$ HPT, half of which can be attributable to multiple endocrine neoplasia (MEN)-I or MEN-II syndromes or familial nonMEN HPT $[1,2]$. Due to its rarity in children, most of the literature on P-HPT in pediatric patients has been limited to case reports and small series [1-4].

Radioactive iodine treatment (RAI) is an accepted treatment for hyperthyroidism associated with Graves' disease and metastatic papillary thyroid carcinoma (PTC) following surgical resection in adults and children $[5,6]$. Colaço et al. analyzed 47 patients who developed P-HPT following treatment with RAI for benign and malignant disease [7]. A female predominance was observed (89.4\% women), with PHPT occurring at a mean age of $59.4 \pm 13.5$ years. The average latency period to the development of P-HPT after RAI was $13.5 \pm 9.1$ years. In this review, two patients with Graves' disease were less than 18 years old ( 5 and 11 years) at the time of RAI, and time to development of P-HPT was 31 and 22 years, respectively [8]. Surgical pathology in these individuals revealed 4-gland hyperplasia in one and an adenoma in the other. We report a case of a 17 -year-old male who presented with hypercalcemia 2 years following RAI treatment for PTC. To our knowledge, this is the first patient reported with this presumed complication of RAI exposure presenting in the pediatric age range.

\section{Case Presentation}

A 17-year-old male presented to the pediatric emergency room with severe headaches. Past medical history was significant for congenital hydrocephalus requiring ventriculoperitoneal shunting and a congenital vein of Galen aneurysm treated with metal coil embolization in infancy at another institution. In the course of diagnosis and management of the hydrocephalus during childhood, he had had 14 computerized tomographic (CT) studies of the brain. At 15 years, he was diagnosed with PTC metastatic to local lymph nodes in the right neck that was treated with a total thyroidectomy, neck dissection, RAI therapy, and L-thyroxine suppression. There were no postoperative complications. He received two doses of RAI a year apart, a total of 263 millicuries (mCi). Serum 
thyroglobulin (Tg) level off thyroxine prior to second RAI treatment was $6.4 \mathrm{ng} / \mathrm{mL}$, while serum thyroid-stimulating hormone (TSH) was $81 \mu \mathrm{IU} / \mathrm{mL}$, suggesting some residual thyroid-like tissue. Post-I131 treatment total body scan obtained 5 days after the second therapy dose showed uptake in right neck, interpreted as probable residual thyroid cancer. Three months after the second RAI dose, he developed severe headaches and was found to have an intracranial thrombus of the transverse sinus. At this time, serum calcium was $10 \mathrm{mg} / \mathrm{dL}$ and $\mathrm{Tg}$ concentration on thyroxine therapy was $<1 \mathrm{ng} / \mathrm{mL}$. He was treated with anticoagulation for one year. At both 7 and 11 months following the second RAI treatment, surveillance neck ultrasounds revealed the stable appearance of a $1 \mathrm{~cm}$ nodule in the right thyroid bed that was not palpable on physical examination. Fine needle aspirate was planned after stopping anticoagulation therapy. One week after anticoagulation therapy was discontinued, headaches acutely returned prompting the emergency room visit. Brain CT showed progressive, nonocclusive thrombosis of the transverse sinus. Laboratory studies performed during the emergency room visit identified hypercalcemia $(13.1 \mathrm{mg} / \mathrm{dL}$; normal range 8.9-10.7) and hypophosphatemia $(2 \mathrm{mg} / \mathrm{dL}$; normal range 3.0-5.2), with a concomitant intact PTH of $154 \mathrm{pg} / \mathrm{mL}$ (normal range 9-69). Anticoagulant therapy was resumed. Neck ultrasound and technetium $\left({ }^{99 \mathrm{~m}} \mathrm{Tc}\right)$ sestamibi scan were consistent with a hyperfunctioning right parathyroid adenoma (Figure 1). Prior to proceeding with surgical excision, recombinant thyrotropin-stimulated serum Tg concentration was $<1 \mathrm{ng} / \mathrm{mL}$ and total body $4 \mathrm{mCi}$ I 131 scan was negative. The patient underwent removal of a $1.5 \mathrm{~cm}$ right parathyroid adenoma with benign histology. Fifteen hours postoperatively, serum PTH and calcium were $<3 \mathrm{pg} / \mathrm{mL}$ and $9.3 \mathrm{mg} / \mathrm{dL}$, respectively. The patient was transiently treated with calcium supplementation and remained eucalcemic 2 years following surgery. Follow-up neck ultrasound at 2 years reveals no nodules.

\section{Discussion}

Hyperparathyroidism was first reported following external beam radiation in 1975 and has subsequently been described following head and neck radiation for benign and malignant conditions and among atomic bomb survivors of Hiroshima [9-11]. Cohen et al. evaluated a cohort of 4297 patients who received radiation to the tonsils before the age of 16 years and were followed prospectively. The incidence of clinical hyperparathyroidism was increased approximately 2.5 -fold over the general population and the latency period was 20 to 46 years [12]. McMullen et al. recently reported the incidental finding of unsuspected hyperparathyroidism largely due to adenoma in $10 \%$ of 53 patients referred for nodular thyroid disease following radiation for childhood cancer [13]. Latency period was 15 to 34 years. Estimated radiation exposure to the neck was 90-1320 centigray (cGy). In the adult literature, hyperparathyroidism is a rare occurrence following RAI treatment, which is observed mostly in females and with an average latency period of 15-20 years following RAI exposure [7]. Hyperparathyroidism following RAI in pediatric patients treated for Graves' disease is reported, but typically occurs

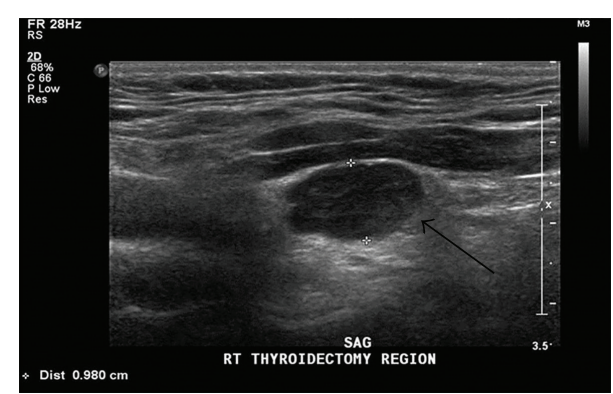

Thyroid ultrasound

(a)

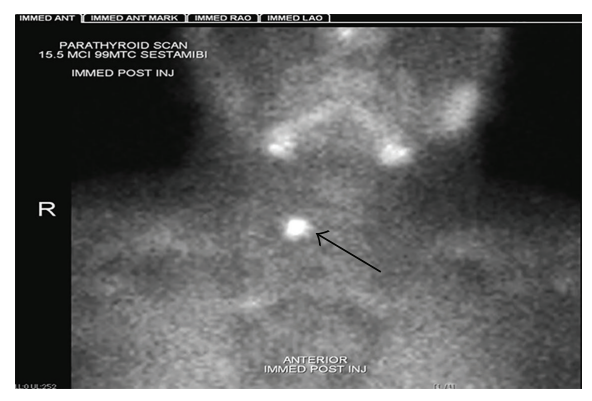

Technetium $\left({ }^{99 \mathrm{~m}} \mathrm{Tc}\right)$ sestamibi scan

(b)

Figure 1: Ultrasound (a) and technetium $\left({ }^{99 \mathrm{~m}} \mathrm{Tc}\right)$ sestamibi scan (b) of nonpalpable $1 \mathrm{~cm}$ nodule in right neck prior to removal of parathyroid adenoma.

during adulthood, more than a decade later $[8,14]$. We found a single report of hyperparathyroidism occurring in a pediatric thyroid cancer patient at the age of 22 years treated with $103 \mathrm{mCi}$ of RAI at age 9 years [15]. Hypoparathyroidism has also been reported following RAI and is usually transient [16-18].

Estimated dose to the parathyroids following treatment of Graves' disease (doses 2-38 mCi) is 140 to $750 \mathrm{cGy}$ [19]. Our patient received a total RAI dose of $263 \mathrm{mci}$, 10 -fold higher than that typically administered for Graves' disease. The incidence of hyperparathyroidism has been suggested to increase with the dose of radiation exposure $[20,21]$ and younger age at exposure [15]. Studies of radiation-exposed populations have demonstrated a much greater sensitivity to radiation in children compared with adults, presumably in part due to greater mutagenic effects of radiation in growing children's tissues, which are replicating at a faster rate [22]. Doses as small as $50-100 \mathrm{mGy}$ have been associated with an increased risk of thyroid malignancy in children, with a linear dose-response up to about 10-20 Gy after which the risk appears to level off [23-25]. This excess risk persists for at least four decades after exposure [23]. Our patient had numerous CT scans as a young child, estimated to yield a cumulative exposure of 20-40 cGy to the head in addition to that from RAI [26]. The contribution of radiation exposure from early CT scans to our patient's thyroid cancer and/or hyperparathyroidism is unclear.

Pediatricians are well aware that hypoparathyroidism is a known complication of thyroidectomy and thyroid cancer 
surgery. In patients who do not have postoperative hypocalcemia, calcium levels may not subsequently be monitored. Our patient demonstrates that, while rare, hyperparathyroidism may occur following a short latency period after RAI. We recommend that serum calcium levels be included in routine yearly surveillance of these patients, particularly in those with a history of additional radiation exposure.

\section{Conflict of Interests}

The authors declare that there is no conflict of interests regarding the publication of this paper.

\section{References}

[1] J. Kollars, A. E. Zarroug, J. Van Heerden et al., "Primary hyperparathyroidism in pediatric patients," Pediatrics, vol. 115, no. 4, pp. 974-980, 2005.

[2] R. Belcher, A. M. Metrailer, D. L. Bodenner, and B. C. Stack Jr., "Characterization of hyperparathyroidism in youth and adolescents: a literature review," International Journal of Pediatric Otorhinolaryngology, vol. 77, pp. 318-322, 2013.

[3] I. Pashtan, R. H. Grogan, S. P. Kaplan et al., "Primary hyperparathyroidism in adolescents: the same but different," Pediatric Surgery International, vol. 29, pp. 275-279, 2013.

[4] C.-C. Li, C. Yang, S. Wang, J. Zhang, X.-R. Kong, and J. Ouyang, "A 10-year retrospective study of primary hyperparathyroidism in children," Experimental and Clinical Endocrinology and Diabetes, vol. 120, no. 4, pp. 229-233, 2012.

[5] S. A. Rivkees, C. Sklar, and M. Freemark, "The management of Graves' disease in children, with special emphasis on radioiodine treatment," Journal of Clinical Endocrinology and Metabolism, vol. 83, no. 11, pp. 3767-3775, 1998.

[6] D. S. Cooper, G. M. Doherty, B. R. Haugen et al., "Revised American thyroid association management guidelines for patients with thyroid nodules and differentiated thyroid cancer," Thyroid, vol. 19, no. 11, pp. 1167-1214, 2009.

[7] S. M. Colaço, M. Si, E. Reiff, and O. H. Clark, "Hyperparathyroidism after radioactive iodine therapy," American Journal of Surgery, vol. 194, no. 3, pp. 323-327, 2007.

[8] C. B. Esselstyn Jr., O. P. Schumacher, and J. Eversman, "Hyperparathyroidism after radioactive iodine therapy for Graves disease," Surgery, vol. 92, no. 5, pp. 811-813, 1982.

[9] I. B. Rosen, H. G. Strawbridge, and J. Bain, "A case of hyperparathyroidism associated with radiation to the head and neck area," Cancer, vol. 36, no. 3, pp. 1111-1114, 1975.

[10] L. E. Tisell, S. Carlsson, and M. Fjalling, "Hyperparathyroidism subsequent to neck irradiation," Cancer, vol. 56, no. 7, pp. 15291533, 1985.

[11] S. Fujiwara, R. Sposto, H. Ezaki et al., "Hyperparathyroidism among atomic bomb survivors in Hiroshima," Radiation Research, vol. 130, no. 3, pp. 372-378, 1992.

[12] J. Cohen, T. C. Gierlowski, and A. B. Schneider, "A prospective study of hyperparathyroidism in individuals exposed to radiation in childhood," Journal of the American Medical Association, vol. 264, no. 5, pp. 581-584, 1990.

[13] T. McMullen, G. Bodie, A. Gill et al., "Hyperparathyroidism after irradiation for childhood malignancy," International Journal of Radiation Oncology Biology Physics, vol. 73, no. 4, pp. 1164-1168, 2009.
[14] C. H. Read Jr., M. J. Tansey, and Y. Menda, "A 36-year retrospective analysis of the efficacy and safety of radioactive iodine in treating young Graves' patients," Journal of Clinical Endocrinology and Metabolism, vol. 89, no. 9, pp. 4229-4233, 2004.

[15] A.-G. Bondeson, L. Bondeson, and N. W. Thompson, "Hyperparathyroidism after treatment with radioactive iodine: not only a coincidence?" Surgery, vol. 106, no. 6, pp. 1025-1027, 1989.

[16] M. Fjalling, A. Dackenberg, I. Hedman, and L. E. Tisell, "An evaluation of the risk of developing hyperparathyroidism after ${ }^{131}$ I treatment for thyrotoxicosis," Acta Chirurgica Scandinavica, vol. 149, no. 7, pp. 681-686, 1983.

[17] M. Fulop, "Hypoparathyroidism after ${ }^{131}$ I therapy," Annals of Internal Medicine, vol. 75, no. 5, p. 808, 1971.

[18] M. C. Orme and M. E. Conolly, "Hypoparathyroidism after iodine-131 treatment of thyrotoxicosis," Annals of Internal Medicine, vol. 75, no. 1, pp. 136-137, 1971.

[19] W. M. Burch and J. T. Posillico, "Hypoparathyroidism after I131 therapy with subsequent return of parathyroid function," Journal of Clinical Endocrinology and Metabolism, vol. 57, no. 2, pp. 398-401, 1983.

[20] A. B. Schneider, T. C. Gierlowski, E. Shore-Freedman, M. Stovall, E. Ron, and J. Lubin, "Dose-response relationships for radiation-induced hyperparathyroidism," Journal of Clinical Endocrinology and Metabolism, vol. 80, no. 1, pp. 254-257, 1995.

[21] E. Holmberg, A. Wallgren, L.-E. Holm, M. Lundell, and P. Karlsson, "Dose-response relationship for parathyroid adenoma after exposure to ionizing radiation in infancy," Radiation Research, vol. 158, no. 4, pp. 418-423, 2002.

[22] B. Sinnott, E. Ron, and A. B. Schneider, "Exposing the thyroid to radiation: a review of its current extent, risks, and implications," Endocrine Reviews, vol. 31, no. 5, pp. 756-773, 2010.

[23] E. Ron, J. H. Lubin, R. E. Shore et al., "Thyroid cancer after exposure to external radiation: a pooled analysis of seven studies," Radiation Research, vol. 141, no. 3, pp. 259-277, 1995.

[24] E. Ron, B. Modan, D. Preston, E. Alfandary, M. Stovall, and J. D. Boice Jr., "Thyroid neoplasia following low-dose radiation in childhood," Radiation Research, vol. 120, no. 3, pp. 516-531, 1989.

[25] A. J. Sigurdson, C. M. Ronckers, A. C. Mertens et al., "Primary thyroid cancer after a first tumour in childhood (the Childhood Cancer Survivor Study): a nested case-control study," The Lancet, vol. 365, no. 9476, pp. 2014-2023, 2005.

[26] National Cancer Institute at the National Institutes of Health, "Radiation risks and pediatric computed tomography. A guide for healthcare providers," http://www.cancer.gov/cancertopics/ causes/radiation/radiation-risks-pediatric-CT. 


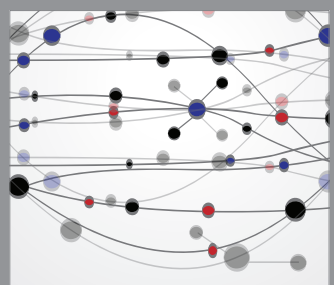

The Scientific World Journal
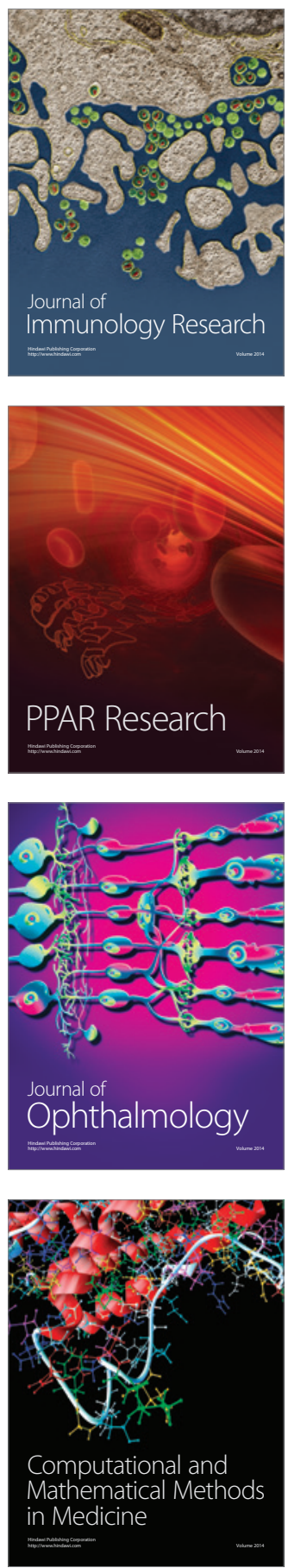

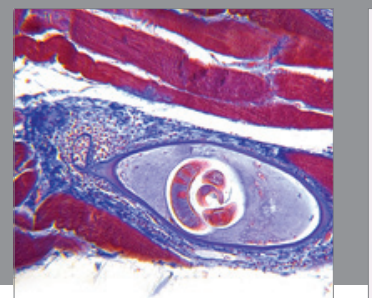

Gastroenterology

Research and Practice
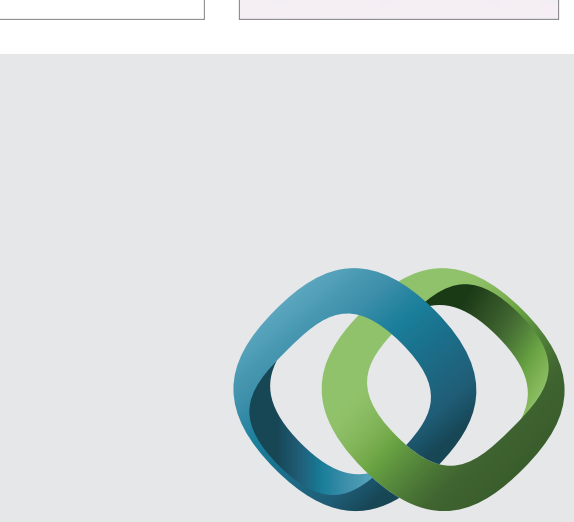

\section{Hindawi}

Submit your manuscripts at

http://www.hindawi.com
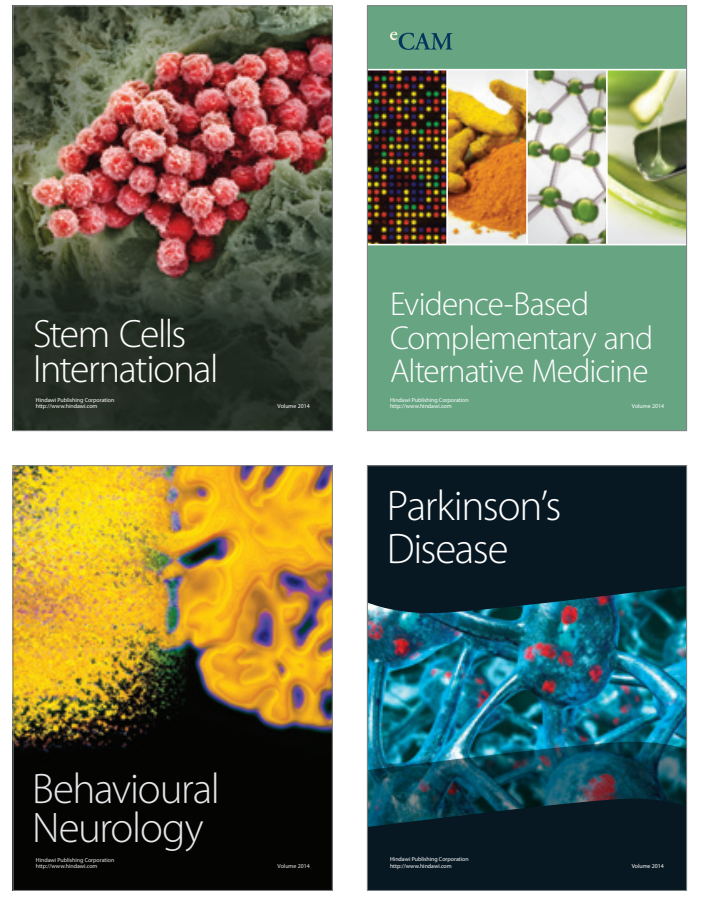
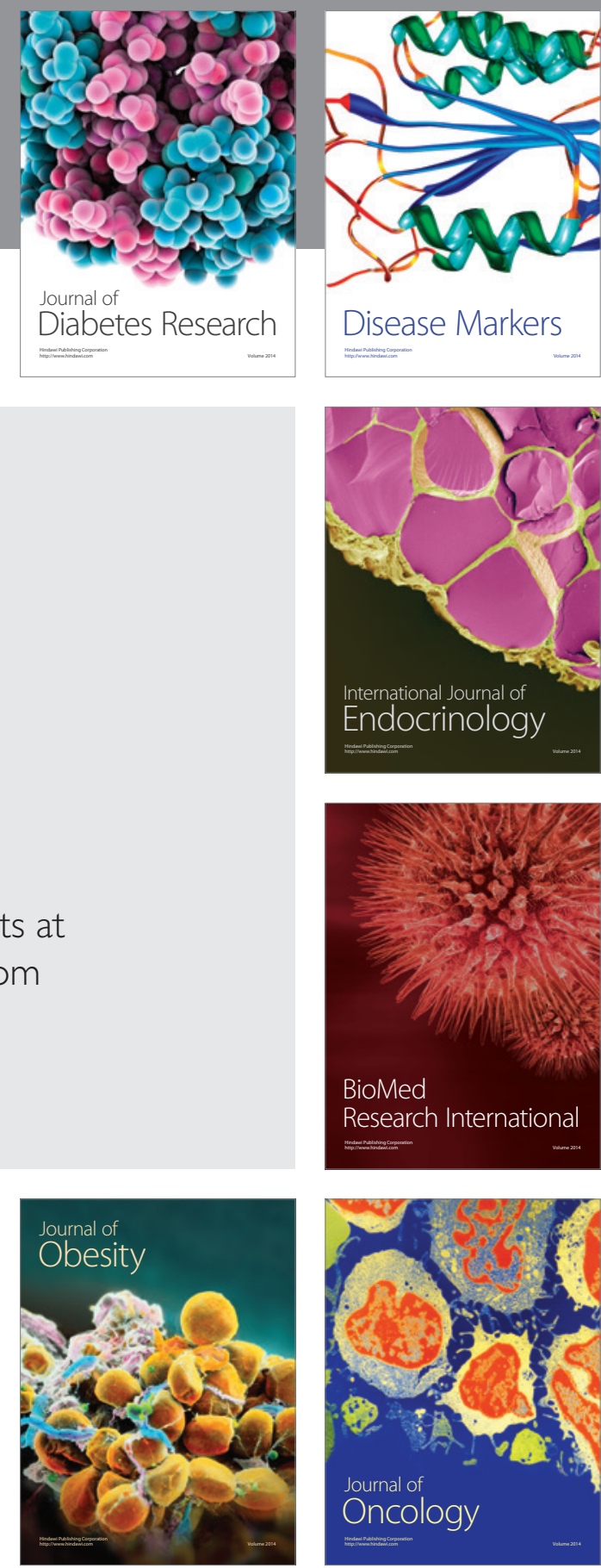

Disease Markers
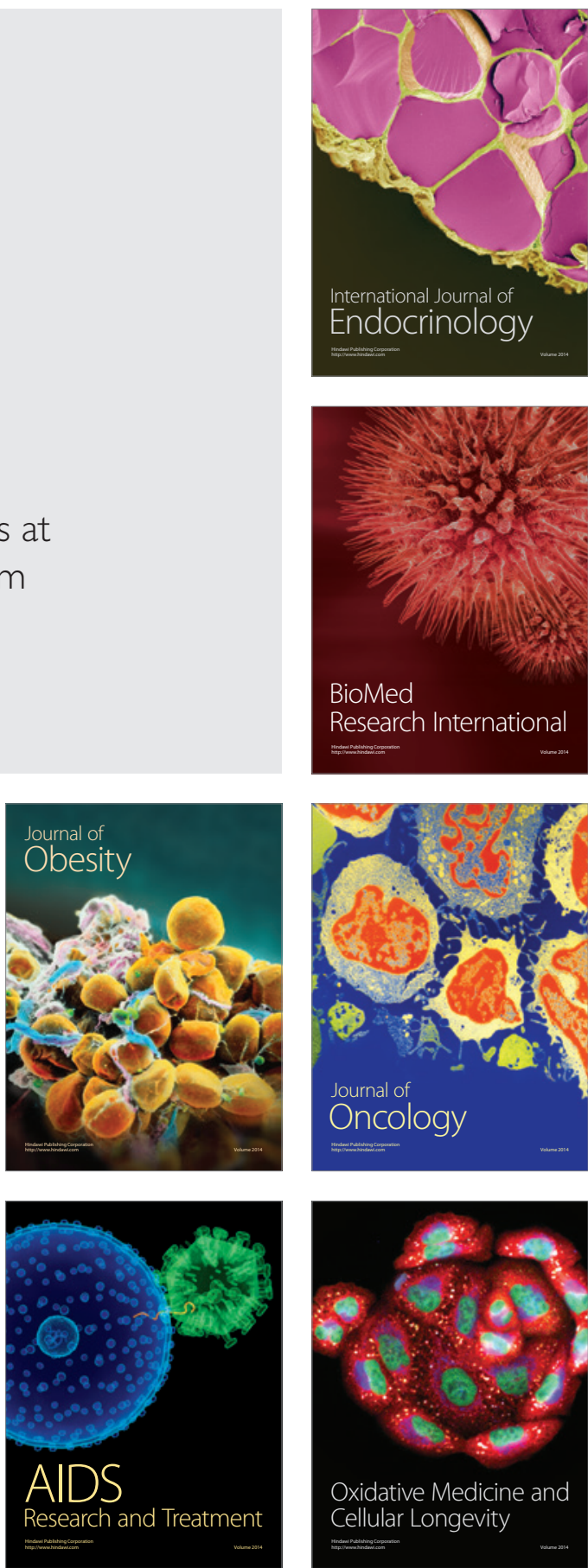